\title{
Estimation of genetic parameters for milk yield across lactations in mixed-breed dairy goats
}

\author{
S. Mucha, ${ }^{1}$ R. Mrode, M. Coffey, and J. Conington \\ Animal \& Veterinary Sciences, Scotland's Rural College, Easter Bush, Midlothian EH25 9RG, United Kingdom
}

\begin{abstract}
Currently, breeding values for dairy goats in the United Kingdom are not estimated and selection is based only on phenotypes. Several studies from other countries have applied various methodologies to estimate breeding values for milk yield in dairy goats. However, most of the previous analyses were based on relatively small data sets, which might have affected the accuracy of the parameter estimates. The objective of this study was to estimate genetic parameters for milk yield in crossbred dairy goats in lactations 1 to 4 . The research was based on data provided by 2 commercial goat farms in the United Kingdom comprising 390,482 milk yield records on 13,591 dairy goats kidding between 1987 and 2012. The population was created by crossing 3 breeds: Alpine, Saanen, and Toggenburg. In each generation, the best-performing animals were selected for breeding and, as a result, a synthetic breed was created. The pedigree file contained 28,184 individuals, of which 2,414 were founders. The data set contained test-day records of milk yield, lactation number, farm, age at kidding, and year and season of kidding. Data on milk composition was unavailable. Covariance components were estimated with the average information REML algorithm in the ASReml package (VSN International Ltd., Hemel Hempstead, UK). A random regression animal model for milk yield with fixed effects of herd test day, year-season, and age at kidding was used. Heritability was the highest at 200 and $250 \mathrm{~d}$ in milk (DIM), reaching 0.45 in the first lactation and between 0.34 and 0.25 in subsequent lactations. After 300 DIM, the heritability started decreasing to 0.23 and 0.10 at 400 DIM in the first and subsequent lactations, respectively. Genetic correlation between milk yield in the first and subsequent lactations was between 0.16 and 0.88. This study found that milk yields in first and subsequent lactations are highly correlated, both at the genetic and phenotypic level. Estimates of heritability for milk yield were higher than most of the values
\end{abstract}

Received July 30, 2013.

Accepted December 22, 2013.

${ }^{1}$ Corresponding author: sebastian.mucha@sruc.ac.uk reported in the literature, although they were in the range reported in this species. This should facilitate genetic improvement for the population studied as part of a broader multi-trait breeding program.

Key words: milk yield, dairy goat, random regression

\section{INTRODUCTION}

Currently, breeding values for dairy goats in the United Kingdom (UK) are not estimated and selection is based only on phenotypes. Unlike in dairy cattle, no centralized recording system exists. Most goat farms are small, with only several animals. Many hobby breeders also exist, who are not interested in production improvement. Few large herd goat breeders conduct their breeding programs independently of each other with hardly any exchange of data. Therefore, estimates of genetic parameters for the UK dairy goats are unknown. Estimation of heritability of milk yield along with correlations with other traits is essential to set up an effective breeding program. It is essential to predict both the direct and correlated response to selection, and to develop a selection index that includes traits of economic importance. Moreover, it is important to raise awareness and benefits of genetic indices among breeders who currently use only raw yields. Routine breeding value estimation is performed, for instance, in such countries as Canada, France, the United States, and Norway (Bélichon et al., 1999; Montaldo and Manfredi, 2002). Unfortunately in the UK, no organized selection program exists, which may negatively affect the genetic level of the population and reduce its profitability compared with goat populations from other countries.

Several other studies have applied various methodologies to estimate breeding values for milk yield in dairy goats. These include models for lactation total milk yield (Valencia et al., 2005) and 250-d cumulated milk yield (Rupp et al., 2011) as well as the repeatability of milk yield and random regression models using testday records (Zumbach et al., 2008). Random regression models have been proven as good tools for estimation of genetic parameters in dairy goats (Zumbach et al., 2008; Menéndez-Buxadera et al., 2010). The use of a random regression model allows better insight into the relation- 
ship between the traits under investigation compared with a single-point estimate of heritability from lactation yield models. Random regression test-day models are more flexible compared with test-day models with a fixed lactation curve, as it seems to better account for the shape of the lactation curves, allowing each animal to have a different shape of lactation as determined at the genetic level (Jamrozik et al., 1997).

One problem in the estimation of genetic parameters for dairy goats is the availability of sufficient high-quality data. Many of the reports present in the literature were based on relatively small data sets, which might have affected the accuracy of the parameter estimates. Moreover, previous analyses were mostly limited to 305 DIM, which is based on dairy cattle evaluations. In the case of goats, they are often milked for lactations that extend past $400 \mathrm{~d}$. However in the UK, no previous study has been done on the estimation of genetic parameters for goat milk production.

Therefore, the objective of this study was to estimate heritability for milk yield, across $400 \mathrm{~d}$ of lactation, in a synthetic population of crossbred dairy goats for lactations 1 to 4 . Genetic and phenotypic correlations between milk yield in the first and subsequent lactations were estimated. This information will provide the basis for development of routine breeding value estimation for UK dairy goats.

\section{MATERIALS AND METHODS}

\section{Data}

The lactation data were from 2 separate farm units in the UK, owned by a single farming business. The herds used for this study are larger than other units operating in the UK, although several herds exist with $400+$ dairy goats undertaking routine milk recording and using electronic identification to facilitate data recording. The business is considered to be the most technically advanced in the UK, although it works closely with other milk producers that supply milk into the same commercial milk processing enterprise. The data set comprised 390,482 records on 13,591 dairy goats kidding between 1987 and 2012. The population was created in 1985 by crossing 3 breeds: Alpine, Saanen, and Toggenburg. No particular crossing strategy existed. In each generation, the best-performing animals were selected for breeding and, as a result, a synthetic breed was created. The breed composition of the animals was not recorded and, thus, could not be included in the analysis. To mitigate this problem, SNP information was used to asses breed composition of the animals. A total of 1,961 goats from the same population were genotyped with the Illumina Caprine 50K BeadChip (Illumina Inc., San Diego, CA;
Tosser-Klopp et al., 2012). Clustering based on principal components analysis, performed with SNP \& Variation Suite v7.7.8 (Golden Helix Inc., Bozeman, MT), did not reveal any major distinct groups. This suggests that the analyzed population is mostly homogeneous and, therefore, breed was not included as a factor in the analysis. The pedigree file contained 28,184 individuals, of which 2,414 were considered as founders. There were 318 sires and 10,781 dams in the pedigree. The data set contained test-day records of milk yield, along with information about lactation number (1 to 4), farm (2 farms), age at kidding (12 to $90 \mathrm{mo}$ ), and year (1987 to 2012) and season of kidding [summer (June to August), autumn (September to November), winter (December to February), and spring (March to May)]. Fat and protein content was not included in the analysis, as it had not yet been recorded on either of the 2 farms that contributed data. Litter size was recorded only for some of the animals and, as a result, only 170,710 milk records could be matched with litter size records. Only goats with more than 3 test-day observations were used for analysis. Additionally, the data set was restricted to have at least 10 records per level of herd-test-day, year-season, and age at kidding. Test-day milk records below 0.5 and above $12 \mathrm{~kg}$ were removed from the data as error records. Lactation length was restricted to between 4 and 400 DIM because goats from the 2 farms are milked for long lactations. The target age for first kidding is $12 \mathrm{mo}$ and average lactation length is $18 \mathrm{mo}$. Animals are milked 3 times per day in the first stage of lactation and twice when milk production decreases. Unfortunately, the number of milking occasions associated with each daily yield was not recorded. Goats are fed with high-DM grass silage. Metabolizable energy content of the diet was around 11.1 to $11.4 \mathrm{MJ} / \mathrm{kg}$ of DM at $16 \% \mathrm{CP}$.

\section{Estimation of (Co) Variance Components}

Covariance components were estimated with the average information REML algorithm in the ASReml package (Gilmour et al., 2009). The following random regression animal model for milk yield was used:

$$
\mathbf{y}=\mathbf{X b}+\mathbf{Z} \mathbf{a}+\mathbf{W} \mathbf{p}+\mathbf{e},
$$

where $\mathbf{y}$ is the vector of test-day observations; $\mathbf{b}$ the vector of fixed effects, consisting of herd test day, year-season, and fixed lactation curves modeled by fitting Legendre polynomials (Kirkpatrick et al., 1990) of fourth order nested within age at kidding; $\mathbf{a}$ is a 1 $\times 3$ vector of random regression coefficients (Legendre polynomials of second order) for the animal effect; $\mathbf{p}$ is the $1 \times 3$ vector of random regression coefficients 
(Legendre polynomials of second order) for the permanent environment effect; and $\mathbf{e}$ is the vector of random residual effect. The matrix $\mathbf{X}$ is the incidence matrix for fixed effects; $\mathbf{Z}$ and $\mathbf{W}$ are matrices of Legendre polynomials of DIM of second order for random animal and permanent environment effect, respectively. Second-order Legendre polynomials for random effects were chosen because higher orders led to convergence issues and the analysis was more time consuming due to the increased number of equations. Constant residual variance across lactation was assumed, as the initial analysis with heterogeneous residual variance indicated that it does not change much during lactation, varying between 0.2 and 0.3 . After an initial analysis with the smaller data set $(\mathrm{n}=170,710)$ referred to earlier, litter size was excluded from the model, as it did not have a significant effect on the parameter estimations. The largest difference between parameters from the model with and without litter size effect was 0.005 . Litter size had a minimal effect on breeding value estimation, as the correlation between EBV from the 2 models was 0.99 .

Random effects were assumed to be normally distributed with zero means and the following covariance structure:

$$
\operatorname{Var}\left[\begin{array}{c}
\mathbf{a} \\
\mathbf{p} \\
\mathbf{e}
\end{array}\right]=\left[\begin{array}{ccc}
\mathbf{A} \otimes \mathbf{G} & 0 & 0 \\
& \mathbf{I} \otimes \mathbf{P} & 0 \\
\text { symm } & & \mathbf{I} \sigma_{e}^{2}
\end{array}\right],
$$

where $\mathbf{A}$ is the additive genetic relationship matrix; $\mathbf{G}$ and $\mathbf{P}$ are $3 \times 3$ (co)variance matrices of the random regression coefficients for the animal and permanent environment effects, respectively; I are identity matrices; and $\sigma_{e}^{2}$ is the residual variance.

In the bivariate analyses, the following combinations of 2 traits were applied: lactation 1 and 2, lactation 1 and 3, lactation 1 and 4, with the variance-covariance structure defined as follows:

$\operatorname{Var}\left[\begin{array}{c}\mathbf{a}_{1} \\ \mathbf{a}_{2} \\ \mathbf{p}_{1} \\ \mathbf{p}_{2} \\ \mathbf{e}_{1} \\ \mathbf{e}_{2}\end{array}\right]=\left[\begin{array}{cccccc}\mathbf{A} \otimes \mathbf{G}_{1} & \mathbf{A} \otimes \mathbf{G}_{12} & 0 & 0 & 0 & 0 \\ & \mathbf{A} \otimes \mathbf{G}_{2} & 0 & 0 & 0 & 0 \\ & & \mathbf{I} \otimes \mathbf{P}_{1} & \mathbf{I} \otimes \mathbf{P}_{12} & 0 & 0 \\ & & & \mathbf{I} \otimes \mathbf{P}_{2} & 0 & 0 \\ & & & & \mathbf{I} \sigma_{e 1}^{2} & \mathbf{I} \sigma_{e 12} \\ \text { symm } & & & & & \mathbf{I} \sigma_{e 2}^{2}\end{array}\right]$,

where subscripts 1 and 2 indicate the 2 traits. In the bivariate analysis, the data set was restricted so that each animal had records for both traits. The resulting numbers of observations are presented in Table 1.
Table 1. Number of records in the bivariate analyses of milk yield in lactations 1 to 4

\begin{tabular}{lcc}
\hline Lactation & $\mathrm{n}$, trait 1 & $\mathrm{n}$, trait 2 \\
\hline 1 and 2 & 110,861 & 106,119 \\
1 and 3 & 64,208 & 61,255 \\
1 and 4 & 34,718 & 35,111 \\
\hline
\end{tabular}

\section{Calculation of Parameters}

Heritability on the ith DIM for milk yield was calculated in a bivariate analysis of lactation 1 with 2,3 , and 4 as follows:

$$
\hat{h}_{i}^{2}=\frac{\hat{\sigma}_{a i}^{2}}{\hat{\sigma}_{a i}^{2}+\hat{\sigma}_{p i}^{2}+\hat{\sigma}_{e}^{2}},
$$

where $\hat{\sigma}_{a i}^{2}$ and $\hat{\sigma}_{p i}^{2}$ are the estimates of genetic and permanent environment variance, respectively, on the $i$ th DIM, and $\hat{\sigma}_{e}^{2}$ is the estimated residual variance. The genetic and permanent environment variances were calculated as $\hat{\sigma}_{a i}^{2}=\mathbf{L}^{\prime}\left(\mathrm{DIM}_{i}\right) \hat{\mathbf{G}} \mathbf{L}\left(\mathrm{DIM}_{i}\right)$ and $\hat{\sigma}_{p i}^{2}=\mathbf{L}^{\prime}\left(\mathrm{DIM}_{i}\right) \hat{\mathbf{P}} \mathbf{L}\left(\mathrm{DIM}_{i}\right)$, respectively, and $\mathbf{L}^{\prime}(\mathrm{DIM})$ is the row vector of Legendre polynomials for $\mathrm{DIM}_{\mathrm{i}}($ Kirkpatrick et al., 1990), of size 3 .

Genetic $\left(\hat{\sigma}_{g i 12}\right)$ and permanent environment $\left(\hat{\sigma}_{p i 12}\right)$ covariances on the $i$ th DIM were estimated from the bivariate analyses as $\hat{\sigma}_{q i 12}=\mathbf{L}^{\prime}\left(\mathrm{DIM}_{i}\right) \hat{\mathbf{G}}_{12} \mathbf{L}\left(\mathrm{DIM}_{i}\right)$ and $\hat{\sigma}_{p i 12}=\mathbf{L}^{\prime}\left(\operatorname{DIM}_{i}\right) \hat{\mathbf{P}}_{12} \mathbf{L}\left(\mathrm{DIM}_{i}\right)$. The phenotypic covariance was the sum of the genetic, permanent environment, and residual covariances.

Standard errors for heritability and genetic and phenotypic correlations were calculated using the methodology proposed by Fischer et al. (2004), with the interpretation proposed by Frigo et al. (2010).

\section{RESULTS}

Mean, variance, minimum, and maximum values for milk production are presented in Table 2. Milk yield in the first lactation had a mean of $3.32 \pm 0.003 \mathrm{~kg}$. The highest mean was observed in the second lactation, where it reached $3.70 \pm 0.003 \mathrm{~kg}$. The lowest milk yields were observed in the fourth lactation, which had a mean of $3.27 \pm 0.01 \mathrm{~kg}$ (Table 2). In the first lactation, daily milk yield reached a peak value at around $100 \mathrm{~d}$, with $3.97 \mathrm{~kg}$. Subsequent lactations (second to fourth) had an earlier peak at around 60 to $80 \mathrm{~d}$, with $5.00,4.63$, and $4.61 \mathrm{~kg}$ of milk in second, third, and fourth lactation, respectively. After the peak, the highest decrease in milk yield was observed in the third and fourth lactation (Figure 1). Daily yields were the high- 


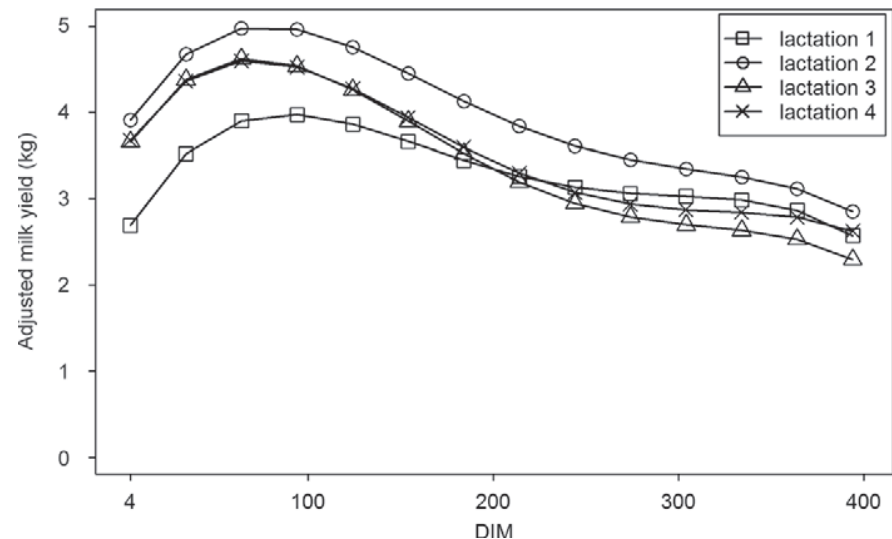

Figure 1. Milk yield in lactations 1 to 4 , adjusted for herd test day, year-season, and age at kidding.

est in the second lactation and decreased in subsequent lactations. Distribution of milk yield in each of the 4 lactations was skewed to the right. A relatively high frequency was observed of low test-day yields of around 0.5 to $0.6 \mathrm{~kg}$.

\section{Heritability Estimates}

Heritability was the highest between 200 and 250 DIM, reaching $0.45 \pm 0.02,0.34 \pm 0.02$, and $0.25 \pm$ 0.03 in the first, second, and third lactation, respectively (Figure 2). After 300 DIM, heritability started decreasing to $0.23 \pm 0.03,0.14 \pm 0.03$, and $0.15 \pm 0.04$ at 400 DIM, respectively. The fourth lactation had a peak of heritability between 150 and 200 DIM, with heritability of $0.28 \pm 0.04$. After 200 DIM, heritability decreased to $0.10 \pm 0.04$. The decline of heritability in all of the analyzed lactations was caused by a large increase in permanent environmental variance. It increased 2-fold in the first, third, and fourth lactation, and 3 -fold in the second lactation. In all lactations, the genetic variance was inflated between 50 and 250 DIM.

\section{Genetic and Phenotypic Correlations}

Milk yield in the first and second lactation had a genetic correlation between $0.57 \pm 0.136$ and $0.88 \pm$

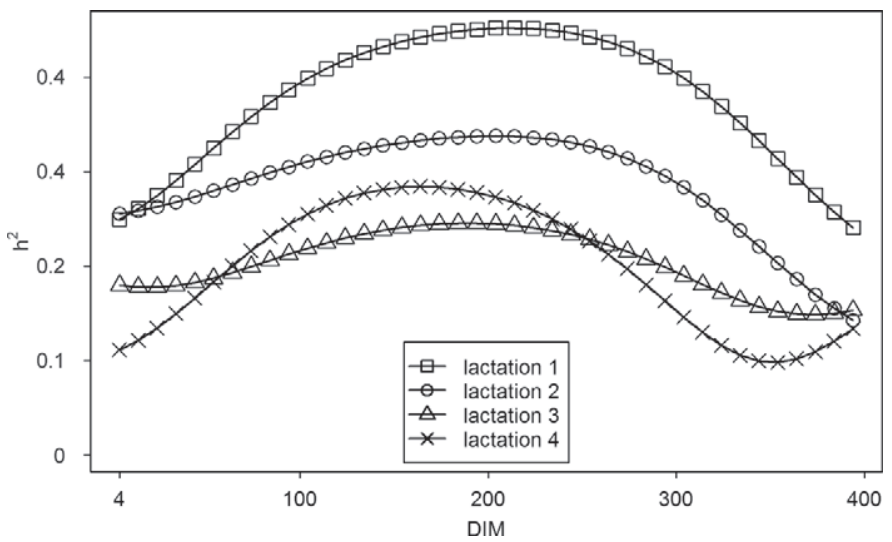

Figure 2. Trend for heritability of milk yield in lactations 1 to 4 of goats during $400 \mathrm{~d}$ of lactation, based on a random regression model.

0.025 (Figure 3). The genetic relationships of the first lactation with lactations 3 to 4 were less persistent. The highest values were between 50 and 100 DIM, reaching $0.75 \pm 0.058$, and $0.67 \pm 0.076$ for genetic correlation of the first lactation with third and fourth lactation, respectively. Phenotypic correlations between milk yield in the first and subsequent lactations followed a similar pattern. They were the highest between 100 and 200 DIM, reaching $0.51 \pm 0.007,0.32 \pm 0.011,0.25 \pm 0.013$ for correlations of the first lactation with second, third, and fourth lactation, respectively. Standard errors for all estimates of genetic correlation were the highest at the end (350 to 400 DIM) of the lactations. In the correlation of milk yield in the first and second lactation, standard errors were lowest at 0.043 , and 0.136 at the beginning and end of lactation, respectively. As the number of records decreased in subsequent lactations, the standard errors increased up to 0.301 and 0.749 at the end of the analyzed period for correlations of the first-lactation milk yield with fourth- and third-lactation yields, respectively. Between 100 and 300 DIM, standard errors were much smaller (0.053 to 0.171). Phenotypic correlations had lower standard errors than the genetic correlations. They were also the highest at the end of the lactations, with values of 0.028 to 0.069 . However, between 100 and 300 DIM, the standard errors were below 0.02 .

Table 2. Mean, minimum, and maximum values, variance, and heritability $\left(\mathrm{h}^{2}\right)$ estimates $( \pm \mathrm{SE})$ for milk yield in lactations 1 to 4

\begin{tabular}{lccccccc}
\hline & & & & & & \multicolumn{2}{c}{$\mathrm{h}^{2}$} \\
\cline { 6 - 8 } Lactation & $\mathrm{n}$ & Mean & Minimum & Maximum & Variance & Minimum & Maximum \\
\hline 1 & 180,447 & 3.32 & 0.60 & 11.60 & 1.59 & $0.23 \pm 0.029$ & $0.45 \pm 0.023$ \\
2 & 109,299 & 3.70 & 0.60 & 11.80 & 2.32 & $0.14 \pm 0.025$ & $0.34 \pm 0.024$ \\
3 & 63,773 & 3.48 & 0.60 & 11.00 & 2.30 & $0.15 \pm 0.035$ & $0.25 \pm 0.029$ \\
4 & 36,963 & 3.27 & 0.60 & 11.10 & 2.22 & $0.10 \pm 0.037$ & $0.28 \pm 0.040$ \\
\hline
\end{tabular}


Table 3. Genetic (upper diagonal) and phenotypic (lower diagonal) correlations within lactation for the firstlactation milk yield

\begin{tabular}{lccccccccc}
\hline & \multicolumn{7}{c}{ DIM } \\
\cline { 2 - 9 } DIM & 5 & 50 & 100 & 150 & 200 & 250 & 300 & 350 & 400 \\
\hline 5 & & 0.90 & 0.72 & 0.59 & 0.51 & 0.46 & 0.43 & 0.41 & 0.36 \\
50 & 0.71 & & 0.95 & 0.88 & 0.83 & 0.78 & 0.74 & 0.66 & 0.49 \\
100 & 0.54 & 0.72 & & 0.98 & 0.96 & 0.93 & 0.88 & 0.78 & 0.55 \\
150 & 0.41 & 0.64 & 0.77 & & 0.99 & 0.97 & 0.93 & 0.83 & 0.59 \\
200 & 0.32 & 0.58 & 0.74 & 0.80 & & 0.99 & 0.96 & 0.87 & 0.64 \\
250 & 0.27 & 0.52 & 0.69 & 0.77 & 0.81 & & 0.99 & 0.92 & 0.71 \\
300 & 0.25 & 0.46 & 0.61 & 0.69 & 0.75 & 0.80 & & 0.97 & 0.81 \\
350 & 0.24 & 0.36 & 0.46 & 0.53 & 0.61 & 0.69 & 0.79 & & 0.93 \\
400 & 0.23 & 0.24 & 0.26 & 0.30 & 0.38 & 0.50 & 0.65 & 0.80 & \\
\hline
\end{tabular}

Estimates of genetic correlations within the first lactation were high and ranged between 0.36 and 0.90 for 5 and 400 DIM, and 5 and 50 DIM, respectively (Table 3). Phenotypic correlations followed a similar pattern, but with lower values. In the second and third lactation, respective correlations were lower, ranging between -0.02 and 0.92 for the second lactation and between 0.12 and 0.88 for the third lactation. In the fourth lactation, beginning of the lactation ( 5 to 50 DIM) was negatively correlated with the end of lactation (350 to 400 DIM), with correlations between -0.11 (5 and 350 DIM) to -0.52 (50 and 400 DIM). However, the phenotypic correlations in this period remained positive (between 0.02 and 0.12 ), with the exception of 50 and 400 DIM, where the correlation was -0.07 .

\section{DISCUSSION}

The aim of this study was to estimate genetic parameters for milk yield in dairy goats for the first time in the UK. The study provides a background for breeding

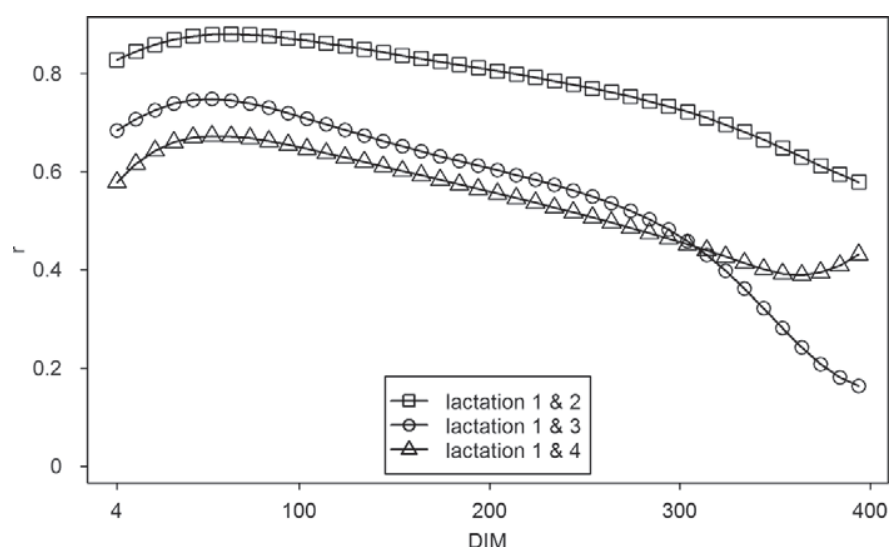

Figure 3. Genetic correlations between milk yield in the first and subsequent (2-4) lactations of British crossbred goats during $400 \mathrm{~d}$ of lactation, based on a random regression model. value estimation and application of EBV as a selection tool. Heritability of milk yield in goats has been estimated in several studies conducted in other countries. Our estimates of heritability are within the range of 0.12 to 0.40 reported in the literature for goats (Boichard et al., 1989; Kala and Prakash, 1990; Torres-Vázquez et al., 2009; Montaldo et al., 2010). However, the shape of trends for heritability in the first lactation was different from those reported by Zumbach et al. (2008) and Menéndez-Buxadera et al. (2010). In the current study, heritability of first-lactation milk yield was the highest in the middle of lactation (200 to 250 DIM) and the lowest at the beginning and end of lactation. Menéndez-Buxadera et al. (2010) estimated the highest heritability at the beginning of lactation $\left(\mathrm{h}^{2}\right.$ above 0.2$)$, which decreased to around 0.1 at the end of lactation. Zumbach et al. (2008) reported a similar tendency, with heritabilities close to 0.4 at the beginning of lactation and decreasing to 0.2 at the end of lactation. Secondlactation milk yield in our study also had a different shape of heritability compared with those 2 studies. Menéndez-Buxadera et al. (2010) presented a curve that fluctuated across lactation, whereas Zumbach et al. (2008) had a stable trend ( $\mathrm{h}^{2}$ of 0.3 ) until 140 DIM, which decreased thereafter to 0.2 . In the current study, heritability for the trait increased until 250 DIM and decreased thereafter. Third-lactation milk yield had a similar shape of heritability, although on a lower level, similar to Zumbach et al. (2008). Low heritability at the end of lactation could be potentially caused by some artifact related to the use of Legendre polynomials and a relatively small number of records after 300 DIM in those lactations in our study.

The curves for heritability presented here (low $h^{2}$ at the beginning and end of lactation) resemble those presented by de Roos et al. (2004) for dairy cattle. However, it has to be noted that because goats in the analyzed population are managed for long lactations, the length of lactation is considerably longer than in 
cattle. An additional analysis with data restricted to 240 DIM was performed to verify if the curves would be similar to those in Zumbach et al. (2008) and Menéndez-Buxadera et al. (2010). However, this analysis only confirmed previous discrepancies with both authors. In all the lactations, heritability curves had the lowest values at the beginning (4 DIM) of lactation, increased with time up to 200 DIM, and had a small decline going toward 240 DIM. It is worth mentioning that, in the current study, the data originated from only 2 farms, which, along with a large number of records, should minimize the effect of environmental noise on our results. On the other hand, the lack of information regarding 3-times- or twice-per-day milking might have led to some underestimation of genetic parameters. This could have had the highest influence at the beginning and end of lactation, where the genetic relationship between milk yield and milking frequency has been reported to be the highest (Nixon et al. 2009).

The genetic correlations between the first- and second-lactation milk yields were higher in the current study compared with other random regression analyses. Zumbach et al. (2008) obtained correlations between 0.6 and 0.8, whereas Menéndez-Buxadera et al. (2010) reported values between 0.5 and 0.8 . In a comparable time period (4-280 DIM), correlation in the current study was between 0.88 and 0.75 . The shape of the correlation obtained in the current research is similar to that of Zumbach et al. (2008), who reported a stable trend across lactations. On the other hand, MenéndezBuxadera et al. (2010) had much more fluctuation in their trend. Our correlation between first- and thirdlactation milk yield was higher than in Zumbach et al. (2008) but was less stable across the lactation. The genetic correlation of the first-lactation milk yield with fourth-lactation yield was smaller and less stable, especially at the end of lactation. This could be partially caused by a considerably smaller number of records in the fourth and fifth lactation, particularly after 300 DIM when only between 20 and 70 observations per test day were available.

In the case of dairy goats, genetic correlations within lactation have not been reported previously. Correlations within the first lactation were similar to those reported in dairy cattle, where the correlation between the beginning and end of lactation was around 0.4 (Strabel and Misztal, 1999). Also, the decline in correlation between the beginning and end of second lactation was similar to that found in cattle (Strabel and Misztal, 1999; Liu et al., 2000). It is worth noting that the negative genetic correlation between the beginning and end of the fourth lactation may indicate that selection for high-yielding animals leads to lower productivity at the end of lactation.
In many of the previously published papers, the number of records available for analysis was very limited, ranging between 440 (Rabasco et al., 1993) and 90,000 records (Zumbach et al., 2008). In the current analysis, the data set was larger and contained 390,487 test-day records. This provides a solid basis for estimation of genetic parameters.

\section{CONCLUSIONS}

This study, using a random regression animal model, showed that milk yield in first and subsequent lactations are highly correlated, both on the genetic and phenotypic level. Estimates of heritability for milk yield were higher than most of the values reported in the literature, although still in the range reported in this species. The work described here should facilitate genetic improvement for the population studied as part of a broader multi-trait breeding program and may also deliver a national breeding program with routine genetic evaluations in the future.

\section{ACKNOWLEDGMENTS}

This paper is part of a 3-yr project co-funded by the UK innovation agency, the Technology Strategy Board (Swindon, UK). The authors gratefully acknowledge cooperation with Angus Wielkopolski and Mark De Hamel from Yorkshire Dairy Goats (Seaton Ross, York, UK).

\section{REFERENCES}

Bélichon, S., E. Manfredi, and A. Piacère. 1999. Genetic parameters of dairy traits in the Alpine and Saanen goat breeds. Genet. Sel. Evol. 31:529-534.

Boichard, D., N. Bouloc, G. Ricordeau, A. Piacere, and F. Barillet 1989. Genetic parameters for first lactation dairy traits in the Alpine and Saanen goat breeds. Genet. Sel. Evol. 21:205-215.

de Roos, A. P. W., A. G. F. Harbers, and G. De Jong. 2004. Random herd curves in a test-day model for milk, fat, and protein production of dairy cattle in the Netherlands. J. Dairy Sci. 87:2693-2701.

Fischer, T. M., A. R. Gilmour, and J. H. J. van der Werf. 2004. Computing approximate standard errors for genetic parameters derived from random regression models fitted by average information REML. Genet. Sel. Evol. 36:363-369.

Frigo, E., C. D. Dechow, O. Pedron, and B. G. Cassell. 2010. The genetic relationship of body weight and early-lactation health disorders in two experimental herds. J. Dairy Sci. 93:1184-1192.

Gilmour, A. R., B. J. Gogel, B. R. Cullis, and R. Thompson. 2009. ASReml User Guide. Release 3.0. VSN International Ltd., Hemel Hempstead, UK.

Jamrozik, J., L. R. Schaeffer, and J. C. M. Dekkers. 1997. Genetic evaluation of dairy cattle using test day yields and random regression model. J. Dairy Sci. 80:1217-1226.

Kala, S. N., and B. Prakash. 1990. Genetic and phenotypic parameters of milk yield and milk composition in two Indian goat breeds. Small Rumin. Res. 3:475-484.

Kirkpatrick, M., D. Lofsvold, and M. Bulmer. 1990. Analysis of the inheritance, selection and evolution of growth trajectories. Genetics 124:979-993. 
Liu, Z., F. Reinhardt, and R. Reents. 2000. Estimating parameters of a random regression test day model for first three lactation milk production traits using the covariance function approach. Interbull Bull. 25:1-7.

Menéndez-Buxadera, A., A. Molina, F. Arrebola, M. J. Gil, and J. M. Serradilla. 2010. Random regression analysis of milk yield and milk composition in the first and second lactations of MurcianoGranadina goats. J. Dairy Sci. 93:2718-2726.

Montaldo, H. H., and E. Manfredi. 2002. Organisation of selection programmes for dairy goats. Pages 1-8 in Proc. 7th World Congr. Genet. Appl. Livest. Prod., Montpellier, France. Institut National de la Recherche Agronomique (INRA), Paris, France.

Montaldo, H. H., G. Torres-Hernández, and M. Valencia-Posadas. 2010. Goat breeding research in Mexico. Small Rumin. Res. 89:155-163.

Nixon, M., J. Bohmanova, J. Jamrozik, L. R. Schaeffer, K. Hand, and F. Miglior. 2009. Genetic parameters of milking frequency and milk production traits in Canadian Holsteins milked by an automated milking system. J. Dairy Sci. 92:3422-3430.

Rabasco, A., J. M. Serradilla, J. A. Padilla, and A. Serrano. 1993. Genetic and non-genetic sources of variation in yield and composition of milk in Verata goats. Small Rumin. Res. 11:151-161.

Rupp, R., V. Clément, A. Piacere, C. Robert-Granié, and E. Manfredi. 2011. Genetic parameters for milk somatic cell score and relation- ship with production and udder type traits in dairy Alpine and Saanen primiparous goats. J. Dairy Sci. 94:3629-3634.

Strabel, T., and I. Misztal. 1999. Genetic parameters for first and second lactation milk yields of Polish black and white cattle with random regression test-day models. J. Dairy Sci. 82:2805-2810.

Torres-Vázquez, J. A., M. Valencia-Posadas, H. Castillo-Juárez, and H. H. Montaldo. 2009. Genetic and phenotypic parameters of milk yield, milk composition and age at first kidding in Saanen goats from Mexico. Livest. Sci. 126:147-153.

Tosser-Klopp, G., P. Bardou, C. Cabau, A. Eggen, T. Faraut, H. Heuven, S. Jamli, C. Klopp, C. T. Lawley, J. McEwan, P. Martin, C. Moreno, P. Mulsant, I. Nabihoudine, E. Pailhoux, I. Palhière, R. Rupp, J. Sarry, B. Sayre, A. Tircazes, J. Wang, W. Wang, T.-P $\mathrm{Yu}$, and W. Zhang. 2012. Goat genome assembly, Availability of an international 50K SNP chip and RH panel: An update of the International Goat Genome Consortium projects. Pages 1-14 in Plant and Animal Genome Conf., San Diego, CA

Valencia, M. P.. J. L. Dobler, and H. H. Montaldo. 2005. Genetic trends for milk yield in a flock of Saanen goats in Mexico. Small Rumin. Res. 57:281-285.

Zumbach, B., S. Tsuruta, I. Misztal, and K. J. Peters. 2008. Use of a test day model for dairy goat milk yield across lactations in Germany. J. Anim. Breed. Genet. 125:160-167. 